\title{
COMPREHENSIVE ASSESSMENT OF DROUGHT RESISTANCE IN SEEDLINGS OF FIVE ALFALFA (MEDICAGO SATIVA L.) CULTIVARS
}

\author{
GUO, H. - GONG, Y. B. - BAO, A. K.* \\ State Key Laboratory of Grassland Agro-ecosystems; Key Laboratory of Grassland Livestock \\ Industry Innovation, Ministry of Agriculture and Rural Affairs; Engineering Research Center of \\ Grassland Industry, Ministry of Education; College of Pastoral Agriculture Science and \\ Technology, Lanzhou University, Lanzhou, 730020, P. R. China \\ *Corresponding author \\ e-mail: baoaik@lzu.edu.cn; phone: +86-931-891-3447; fax: +86-931-891-3447
}

(Received $5^{\text {th }}$ Jun 2019; accepted $2^{\text {nd }}$ Sep 2019)

\begin{abstract}
Selecting drought-tolerant alfalfa cultivars is conducive to improve the forage yield in arid and semi-arid areas. In this study, drought resistance of five alfalfa (Medicago sativa L.) cultivars at the seedling stage was analyzed by using agronomic and physiological indicators. After withholding water for 6 days and then re-watering for 4 days, shoot dry weights of "Longdong" and "Daye" were significantly higher than that of the other cultivars. Under drought stress, "Daye" had healthier plasma membrane with the minimum leaf membrane permeability, while the leaf osmotic potential of "Longdong" and "Gannong No. 3" were significantly lower than that of the other three cultivars. Moreover, "Longdong" showed the highest leaf relative water content. According to the combination of above indicators, the relative drought resistance of the five cultivars decreased in order: "Longdong", "Daye", "Gannong No. 3", "Sandili", and "Rambler". This study suggested that "Longdong" and "Daye" might be more suitable for planting in arid and semi-arid regions.
\end{abstract}

Keywords: forages, arid environment, physiological mechanism, agronomic indicators

\section{Introduction}

Drought is one of the most adverse environmental factors causing the reduction of agricultural productivity worldwide (Hassine et al., 2010; Ghaderi et al., 2011). In order to face this challenge, we need to identify suitable crops adapting to drought. Alfalfa (Medicago sativa L.) is the most important legume forage, which is rich in vitamins, minerals and phytonutrients (Xiao et al., 2015; Kumar et al., 2018). Establishing alfalfa pastures has played a more and more important role in ecological environment and livestock production of China (Shi et al., 2017). Alfalfa planting areas in China were significantly extended by $74 \%$ from 2001 to 2013 , and about $70 \%$ of them are distributed in northern China, an arid or semi-arid region with water resource shortage (Lu, 2013). Planting alfalfa cultivars with strong drought resistance is one of the fundamental ways for promoting forage productivity and saving the limited water resources in northern China. However, there is a considerable variation of drought tolerance among existing alfalfa cultivars (Guo et al., 2004). Alfalfa is very sensitive to drought during the seedling stage (Kumar, 2011). Therefore, to evaluate the drought tolerance in the seedling stage is necessary for selecting drought-tolerant alfalfa cultivars.

Drought stress can directly disrupt the water balance, decrease the leaf turgor potential, and damage the cell membrane (Ma et al., 2012). On a physiological level, the most important strategy for plants survival in arid environment is osmotic adjustment, 
by which plants can retain the water and maintain the stability of cell membrane (Quan et al., 2016). Therefore, the physiological indicators such as osmotic potential ( $\Psi s)$, leaf relative water content (RWC) and relative membrane permeability (RMP), were frequently used to evaluate drought resistance of plants (Foster et al., 2012; Cui et al., 2019). However, it is difficult to determine by single physiological indicator and the result tends to unilateralism, since the mechanism of drought resistance in plants is extremely complex (Cattivelli et al., 2008; Wu et al., 2014). On the other hand, the agronomic indicators (such as yield, survival rate, plant height and biomass) are the phenotypes that integrate the various physiological mechanisms in response to stress, but are readily affected by other factors instead of the concerned factor (Noble and Rogers, 1992; Singh et al., 2019). The objective of this study was thus to assess and compare the drought resistance among five alfalfa cultivars at the seedling stage by combining one agronomic indicator (shoot dry weight) and three physiological indicators (leaf RMP, Leaf $\Psi_{S}$ and leaf RWC).

\section{Materials and methods}

\section{Plant materials, growth conditions and treatments}

Seeds of five alfalfa cultivars, "Longdong", "Gannong No.3", "Daye", "Rambler" and "Sandili" collected from the Chinese commercial market were surface sterilized and germinated as described by Bao et al. (2009). The seedlings were transplanted in plastic pots filled with artificial soil with a mixture of perlite, vermiculite and peat moss $(\mathrm{v} / \mathrm{v}$, 1:1:1). Each cultivar was transplanted in 60 pots. All the seedlings were grown in the greenhouse in Lanzhou University $\left(36.03^{\circ} \mathrm{N}, 103.40^{\circ} \mathrm{E}\right.$; elevation $\left.1520 \mathrm{~m}\right)$ under a $16-\mathrm{h}$ photoperiod (the light flux density was approximately $600 \mu \mathrm{mol} / \mathrm{m}^{2} / \mathrm{s}$ ) at $24 \pm 2{ }^{\circ} \mathrm{C}$ and $60 \pm 5 \%$ of relative humidity, watered with 1/8 Hoagland nutrient solution every 2 days, and seedlings in each pot were thinned to 3 plants after 5 days. The pots were continuously watered with 1/8 Hoagland nutrient solution to maximum field waterholding capacity for 15 days, then nutrient solution was withheld for 6 days and rewatered for 4 days. The seedlings in the control group were watered with 1/8 Hoagland nutrient solution normally. Each treatment was repeated three times, and each repetition contained 10 pots (3 plants/pot). Physiological indicators including leaf relative membrane permeability (RMP), leaf osmotic potential $(\Psi S)$ and leaf relative water content (RWC) were measured after water withholding, and shoot dry weight was determined after re-watered.

\section{Measurement of shoot dry weight}

After being re-watered for 4 days, the shoots were cut from stem base of seedlings and rinsed with distilled water, then were dried in an oven at $80^{\circ} \mathrm{C}$ for $48 \mathrm{~h}$ and the dry weights of shoots were weighed.

\section{Measurement of leaf RMP, $\Psi_{s}$ and $R W C$}

After water withholding for 6 days, the leaves were excised from seedlings. Leaf RMP was determined according to the method reported by Bao et al. (2009) using a conductivity meter (EC215, HANNA, Italy). Leaf $\Psi_{S}$ was measured according to the method as described by Wu et al. (2014) using a cryoscopic osmometer (Osmomat-030, 
Gonotec GmbH, Germany). Leaf RWC was calculated through the method mentioned by Ma et al. (2012).

\section{Assessment of drought resistance in five alfalfa cultivars}

According to the method as described by Bao et al. (2009), the data of shoot dry weight, leaf RMP, leaf $\Psi_{S}$ and leaf RWC were converted into relative values (the ratio of value from drought stress to value from control), respectively. Then the relative value of each indicator from each cultivar was standardized by the subordinate function method (Wu et al., 2014). Finally, the relative drought resistance of each cultivars was scored according to standardized values of each indicator by the following formula: $[I$ $(1)+I(2)+I(3)+I(4)] / 4$. Where $I(1-4)$ refer to the standardized value of shoot dry weight, leaf RMP, leaf $\Psi_{s}$ and leaf RWC, respectively.

\section{Statistical analysis}

All data in this study were analyzed by one-way analysis of variance (ANOVA) using SPSS 13.0 (SPSS inc. USA) and Duncan's Multiple Range test was used to detect significant differences among the means $(P<0.05)$.

\section{Results}

\section{Shoot dry weight}

After withholding water for 6 days and then re-watering for 4 days, shoot biomass of each cultivar was significantly reduced. The shoot dry weight of "Rambler" showed the largest decline by $35.8 \%$ and was significantly lower than that of the other cultivars. Shoot dry weights of "Longdong" and "Xinjiang Daye" only decreased by $9.8 \%$ and $12.9 \%$, respectively, and were significantly higher than other three cultivars (Fig. 1).

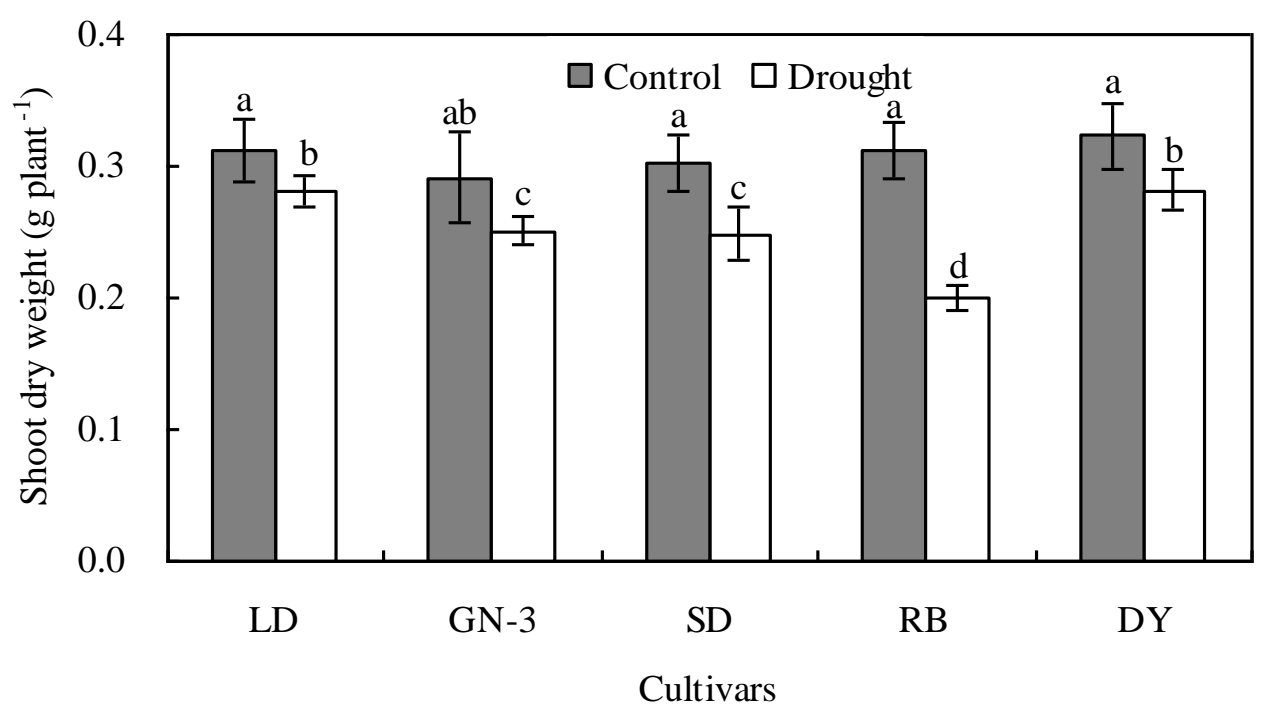

Figure 1. Shoot dry weights of alfalfa seedlings under control and drought conditions for 6 days, and then re-watering for 4 days. Values are means $\pm S D(n=6)$ and bars indicate $S D$. Different letters on columns indicate significant difference at $P<0.05$ (Duncan's test). LD: "Longdong"; GN-3: "Gannong No. 3"; SD: "Sandili"; RB: "Rambler"; DY: "Xinjiang Daye” 


\section{Leaf relative membrane permeability (RMP)}

After being treated with drought for 6 days, leaf RMP of all cultivars increased sharply. However, the leaf RMP of "Longdong" and "Gannong No. 3" were significantly higher than those of the other cultivars, while "Xinjiang Daye" showed the lowest leaf RMP value, under drought stress (Fig. 2).

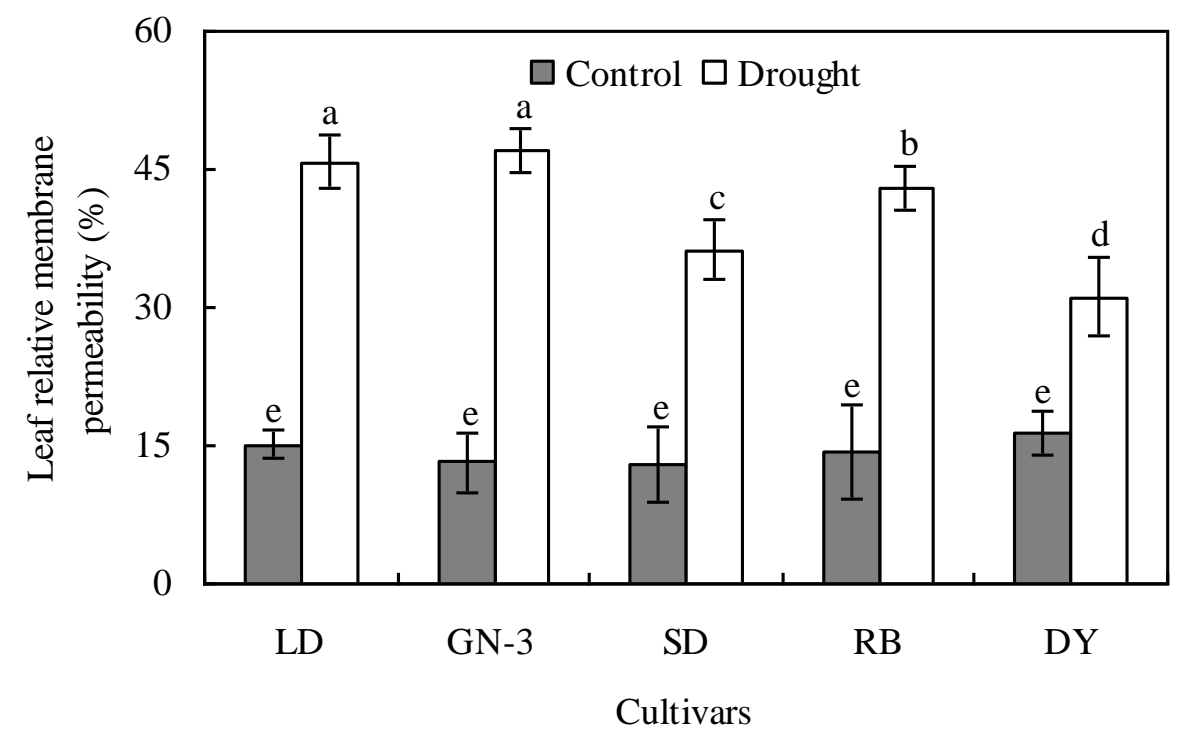

Figure 2. Leaf relative membrane permeabilities of alfalfa seedlings under control and drought conditions for 6 days. Values are means $\pm S D(n=6)$ and bars indicate SD. Different letters on columns indicate significant difference at $P<0.05$ (Duncan's test). LD: "Longdong"; GN-3:

"Gannong No. 3"; SD: "Sandili"; RB: "Rambler"; DY: "Xinjiang Daye”

\section{Leaf osmotic potential ( $\left.\Psi_{s}\right)$}

It is observed that leaf $\Psi_{s}$ of "Longdong" and "Xinjiang Daye" were significantly lower than that of the other three cultivars under the control condition. Under drought stress, leaf $\Psi_{S}$ of each cultivar significantly decreased, but there were significantly differences among five cultivars, in which "Longdong" and "Gannong No. 3" had the lowest leaf $\Psi_{S}$ compared to other three cultivars (Fig. 3).

\section{Leaf relative water content $(R W C)$}

Under well-watering condition, there was no significant difference in leaf RWC between the five alfalfa cultivars. After withholding water for 6 days, leaf RWC of each cultivar was significantly reduced. Moreover, there were significant differences among five cultivars, of which "Rambler" showed the lowest RWC (decreased by 53.0\%), while "Longdong" exhibited the highest RWC (decreased by 35.8\%), under drought stress, suggesting that "Longdong" showed stronger water retention ability than other cultivars (Fig. 4).

\section{Comprehensive assessment on drought resistance among five cultivars}

The relative values of shoot dry weight, leaf RMP, leaf $\Psi_{S}$ and leaf RWC, were used to evaluate and compare the relative drought resistance of five alfalfa cultivars. From 
the comprehensive assessment, the relative drought resistance of the five cultivars decreased in order: "Longdong", "Xinjiang Daye", "Gannong No. 3", "Sandili" and "Rambler". The result of comprehensive evaluation indicated that "Longdong" and "Xinjiang Daye" had relatively higher drought resistance among five cultivars (Table $1)$.

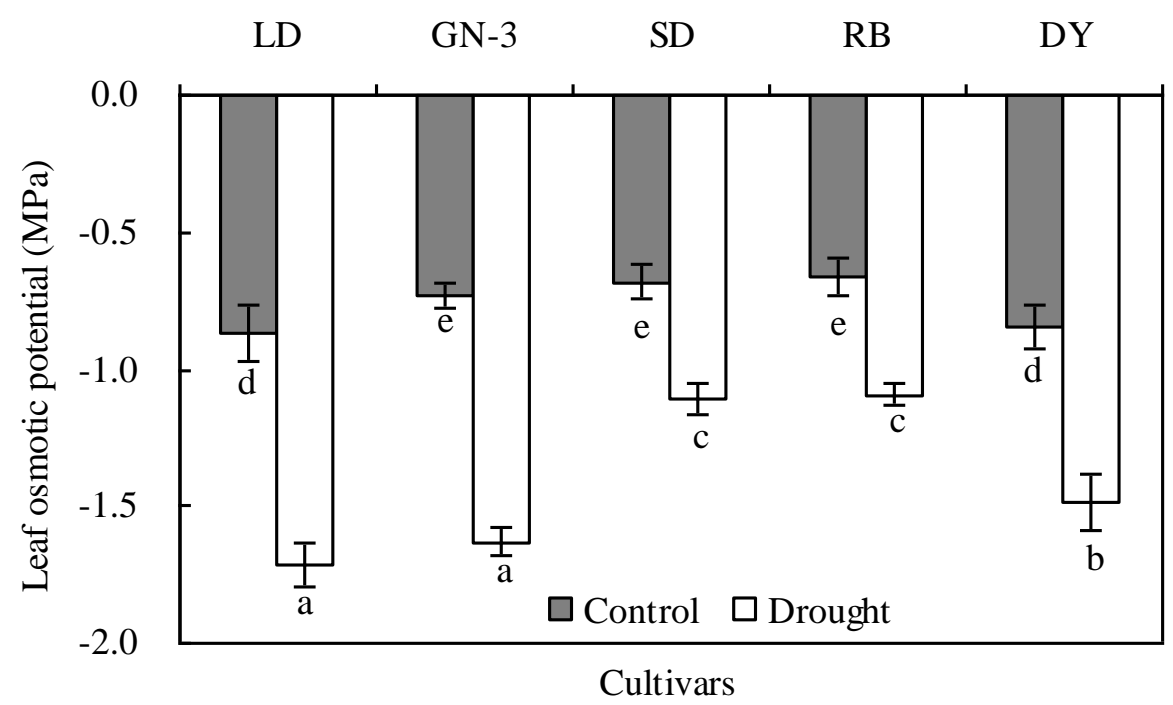

Figure 3. Leaf osmotic potentials of alfalfa seedlings under control and drought conditions for 6 days. Values are means $\pm S D(n=6)$ and bars indicate $S D$. Different letters on columns indicate significant difference at $P<0.05$ (Duncan's test). LD: "Longdong"; GN-3: "Gannong No. 3"; SD: "Sandili"; RB: "Rambler"; DY: "Xinjiang Daye”

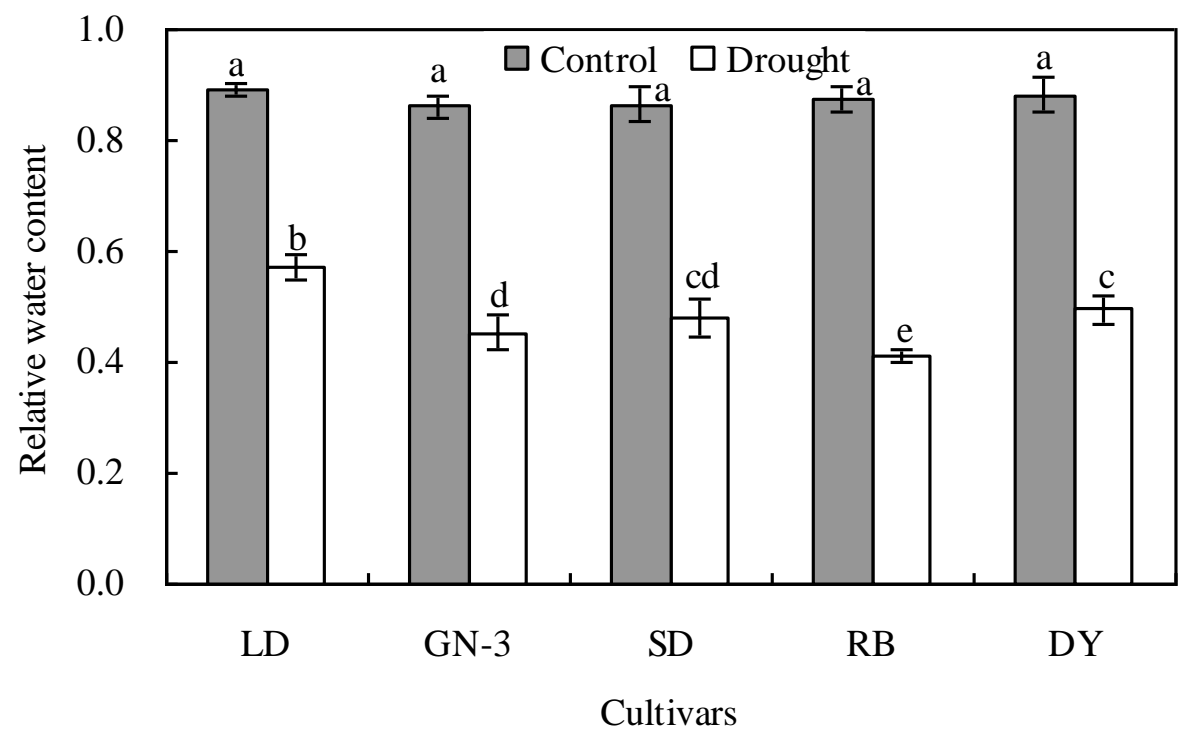

Figure 4. Leaf relative water contents of alfalfa seedlings under control and drought conditions for 6 days. Values are means $\pm S D(n=6)$ and bars indicate SD. Different letters on columns indicate significant difference at $P<0.05$ (Duncan's test). LD: "Longdong"; GN-3: "Gannong No. 3"; SD: "Sandili"; RB: "Rambler"; DY: "Xinjiang Daye" 
Table 1. Comprehensive assessment on drought resistance between the five alfalfa cultivars. I (1): shoot dry weight; I (2): leaf relative membrane permeability; I (3): leaf osmotic potential; I (4): leaf relative water content

\begin{tabular}{c|c|c|c|c|c|c}
\hline Cultivars & $\boldsymbol{I}(\mathbf{1})$ & $\boldsymbol{I}(\mathbf{2})$ & $\boldsymbol{I}(\mathbf{3})$ & $\boldsymbol{I}(\mathbf{4})$ & Mean & Order \\
\hline Longdong & 1.00 & 0.32 & 0.55 & 1.00 & 0.72 & 1 \\
Xinjiang Daye & 0.88 & 1.00 & 0.18 & 0.53 & 0.65 & 2 \\
Gannong No.3 & 0.85 & 0.00 & 1.00 & 0.33 & 0.54 & 3 \\
Sandili & 0.69 & 0.47 & 0.00 & 0.50 & 0.41 & 4 \\
Rambler & 0.00 & 0.30 & 0.03 & 0.00 & 0.08 & 5 \\
\hline
\end{tabular}

\section{Discussion}

As a major abiotic factor, drought can reduce the growth of plants by directly leading to the decrease of shoot yield (Yamaguchi and Sharp, 2010). Therefore, shoot biomass is an important indicator for identifying the stress resistance of higher plants, not only for its ease of measurement, but also due to the fact that it is a direct reaction to the interaction of a variety of physiological mechanisms in plants and external environment (Noble and Rogers, 1992; Wu et al., 2014). Numerous studies have been performed on the effects of drought stress on the seedling growth of alfalfa by focusing on the relationship between water deficit and shoot biomass (Liu et al., 2005; Pang et al., 2011). In the present study, shoot dry weight of five alfalfa cultivars were significantly reduced by water deficit and showed significant difference between cultivars. The similar results were also observed in previous studies on drought response of alfalfa (Kang et al., 2011; Quan et al., 2016). Foliage yield is the primary determinant of plant productivity and economic performance and thus is a momentous criterion for pasture managers to screen cultivars with high-yielding (Liu et al., 2005). Our study demonstrated again that shoot biomass completely can be used as a reliable indicator for evaluating drought resistance in alfalfa cultivars. In addition, this study indicated that other important physiological indicators can also be used as a better basis for assessing the drought resistance of alfalfa cultivars.

Abiotic stresses (including drought) can cause the accumulation of high concentrations of reactive oxygen species (ROS) in plants, which can result in the cell membrane lipid peroxidation, membrane permeability increase and finally inhibit the growth of plants (Wang et al., 2009; Zhang et al., 2018). The ability to maintain stability of membrane structure is closely related to stress resistance of plants, and relative membrane permeability (RMP) is an important indicator reflecting cell membrane stability (Guimarães et al., 2011; Quan et al., 2016). In this study, leaf RMP of five alfalfa cultivars were significantly increased under drought stress, but the increment differed widely among different cultivars. "Xinjiang Daye" showed a significantly lower leaf RMP in comparison to other four cultivars under drought stress, suggesting that it has the relatively higher ability to maintain the stability of membrane structure than other cultivars. This might be resulted from increased antioxidants contents as well as higher antioxidant enzymes activities in drought-tolerant cultivars under drought stress (Kang et al., 2011; Quan et al., 2016).

One of the strategies for plants adapting to arid environment is the accumulation of osmotic adjustment substances, which reduces osmotic potential and thus slows down the water loss of plants (Ma et al., 2012; He et al., 2019). Therefore, the osmotic 
potential $\left(\Psi_{S}\right)$ is an important physiological indicator for measuring the drought tolerance of plants. In this study, "Longdong" and "Gannong No. 3" showed lowest leaf $\Psi_{S}$ under water deficit condition. Interestingly, it was found that leaf $\Psi_{S}$ of "Longdong" and "Xinjiang Daye" were significantly lower than that of the other three cultivars under the normal condition, indicating that their adaptability to drought may be stronger than the other cultivars, since the lower initial leaf $\Psi_{S}$ means the stronger water retention capacity (Mohamed and Tawfik, 2006; Ma et al., 2012). The data of leaf relative water content (RWC) in this study support this point. Under drought stress, "Longdong" had the highest leaf RWC, followed by "Xinjiang Daye", suggesting that these two cultivars have better water status, which may be due to their lower initial osmotic potential. Previous studies have demonstrated that drought-tolerant alfalfa cultivars showed less water loss and higher water use efficiency in drought conditions (Kang et al., 2011; Quan et al., 2016).

Drought resistance of higher plants is a combination of morphological variations, physiological changes, biochemical metabolisms and gene expression regulation, and there are diverse mechanisms and environmental variables involved in drought responses of plants (Wang et al., 2009), thus it actually hard to be accurately clarified by single indicator (Wu et al., 2014; Yan et al., 2015). In the present study, this point was confirmed again. Generally, there are various results presented by different indicators. Therefore, we developed a comprehensive assessment approach through combining one agronomic indicator and three physiological indicators, which are closely related to drought resistance, and especially, can be easily measured at seedling stage of plants. The results of this assessment clearly showed that the performance of "Longdong" and "Xinjiang Daye" were better than the other three alfalfa cultivars under drought stress, suggesting that these two cultivars may be more suitable for planting in arid and semi-arid regions of northern China.

\section{Conclusion}

In this study, we developed a comprehensive assessment procedure for drought resistance of alfalfa seedlings through combining one agronomic indicator and three physiological indicators. The results indicated that there existed great differences in drought resistance among five commercial alfalfa cultivars, in which "Longdong" and "Xinjiang Daye" were more suitable for planting in arid and semi-arid regions of northwestern China, and could be generalized as excellent cultivars with strong resistance. The next step will be to determine the overall adaptability by comprehensively assessing the drought resistance of the different alfalfa cultivars at different growth stages under field conditions, including yield and quality evaluations.

Acknowledgements. This work was supported by the National Key Research and Development Program of China (2017YFC0504804), the National Natural Science Foundation of China $(31670405,31971761)$ and the Fundamental Research Funds for the Central Universities (lzujbky-2018-k01).

\section{REFERENCES}

[1] Bao, A. K., Guo, Z. G., Zhang, H. F., Wang, S. M. (2009): A procedure for assessing the salt tolerance of lucerne (Medicago sativa $\mathrm{L}$.) cultivar seedlings by combining agronomic 
and physiological indicators. - New Zealand Journal of Agricultural Research 52: 435442.

[2] Cattivelli, L., Rizza, F., Badeck, F. W., Mazzucotelli, E., Mastrangelo, A. M., Francia, E., Marè, C., Tondelli, A., Stanca, A. M. (2008): Drought tolerance improvement in crop plants: an integrated view from breeding to genomics. - Field Crops Research 105: 1-14.

[3] Cui, Y. N., Xia, Z. R., Ma, Q., Wang, W. Y., Chai, W. W., Wang, S. M. (2019): The synergistic effects of sodium and potassium on the xerophyte Apocynum venetum in response to drought stress. - Plant Physiology and Biochemistry 135: 489-498.

[4] Foster, K., Ryan, M. H., Real, D., Ramankutty, P., Lambers, H. (2012): Drought resistance at the seedling stage in the promising fodder plant tedera (Bituminaria bituminosa var. albomarginata). - Crop and Pasture Science 63: 1034-1042.

[5] Ghaderi, N., Siosemardeh, A. (2011): Response to drought stress of two strawberry cultivars (cv. kurdistan and selva). - Horticulture Environment and Biotechnology 52: 612 .

[6] Guimarães, F. V., Lacerda, C. F., Marques, E. C., Miranda, M. R., Abreu, C. E., Prisco, J. T., Gomes-Filho, E. (2011): Calcium can moderate changes on membrane structure and lipid composition in cowpea plants under salt stress. - Plant Growth Regulation 65: 5563.

[7] Guo, Z. G., Liu, H. X., Wang, Y. R., Wang, S. M., Cheng, G. D. (2004): Suitability of lucerne cultivars, with respect to root development, to semi-arid conditions in west China. - New Zealand Journal of Agricultural Research 7: 51-59.

[8] Hassine, A. B., Bouzid, S., Lutts, S. (2010): Does habitat of Atriplex halimus L. affect plant strategy for osmotic adjustment? - Acta Physiologiae Plantarum 32: 325-331.

[9] He, F. L., Bao, A. K., Wang, S. M., Jin, H. X. (2019): NaCl stimulates growth and alleviates drought stress the salt-secreting xerophyte Reaumuria soongorica. Environmental and Experimental Botany 162: 433-443.

[10] Kang, Y., Han, Y., Torres-Jerez, I., Wang, M., Tang, Y., Monteros, M., Udvardi, M. (2011): System responses to long-term drought and re-watering of two contrasting alfalfa varieties. - The Plant Journal 68: 871-889.

[11] Kumar, S. (2011): Biotechnological advancements in alfalfa improvement. - Journal of Applied Genetics 52: 111-124.

[12] Kumar, T., Bao, A. K., Bao, Z., Wang, F., Gao, L., Wang, S. M. (2018): The progress of genetic improvement in alfalfa (Medicago sativa L.). - Czech Journal of Genetics and Plant Breeding 54: 41-51.

[13] Liu, H. X., Guo, Z. G., Wang, S. M., Zhang, Z. H., Wang, Y. R. (2005): A new procedure for evaluating lucerne genotypes for semi-arid land in west China. - New Zealand Journal of Agricultural Research 48: 109-116.

[14] Lu, X. S. (2013): Problems with the development of alfalfa industry in China. - Chinese Journal of Grassland 35: 1-5.

[15] Ma, Q., Yue, L. J., Zhang, J. L., Wu, G. Q., Bao, A. K., Wang, S. M. (2012): Sodium chloride improves photosynthesis and water status in the succulent xerophyte Zygophyllum xanthoxylum. - Tree Physiology 32: 4-13.

[16] Mohamed, M. F., Tawfik, A. A. (2006): Dehydration-induced alterations in growth and osmotic potential of callus from six tepary bean lines varying in drought resistance. Plant Cell, Tissue and Organ Culture 87: 255-262.

[17] Noble, C. L., Rogers, M. E. (1992): Arguments for the use of physiological criteria for improving the salt tolerance in crops. - Plant and Soil 146: 99-107.

[18] Pang, J. Y., Yang, J. Y., Ward, P., Siddique, K. H. M., Lambers, H., Tibbett, M., Ryan, M. (2011): Contrasting responses to drought stress in herbaceous perennial legumes. Plant and Soil 348: 299-314.

[19] Quan, W., Liu, X., Wang, H., Chan, Z. (2016): Comparative physiological and transcriptional analyses of two contrasting drought tolerant alfalfa varieties. - Frontiers in Plant Science 6: 1256. 
[20] Shi, S. L., Nan, L. L., Smith, K. F. (2017): The current status, problems, and prospects of alfalfa (Medicago sativa L.) breeding in China. - Agronomy 7: 1.

[21] Singh, R., Srivastava, P., Singh, P., Sharma, A. K., Singh, H., Raghubanshi, A. S. (2019): Impact of rice-husk ash on the soil biophysical and agronomic parameters of wheat crop under a dry tropical ecosystem. - Ecological Indicators 105: 505-515.

[22] Wang, W. B., Kim, Y. H., Lee, H. S., Kim, K. Y., Deng, X. P., Kwak, S. S. (2009): Analysis of antioxidant enzyme activity during germination of alfalfa under salt and drought stresses. - Plant Physiology and Biochemistry 47: 570-577.

[23] Wu, G. Q., Wang, C. M., Su, Y. Y., Zhang, J. J., Feng, R. J., Liang, N. (2014): Assessment of drought tolerance in seedlings of sugar beet (Beta vulgaris L.) cultivars using inorganic and organic solutes accumulation criteria. - Soil Science and Plant Nutrition 60: 565-576.

[24] Xiao, Y., Zhang, J., Jia, T. T., Pang, X. P., Guo, Z. G. (2015): Effects of alternate furrow irrigation on the biomass and quality of alfalfa (Medicago sativa). - Agricultural Water Management 161: 147-154.

[25] Yamaguchi, M., Sharp, R. E. (2010): Complexity and coordination of root growth at low water potentials: recent advances from transcriptomic and proteomic analyses. - Plant, Cell and Environment 33: 590-603.

[26] Yan, W., Zhong, Y., Shangguan, Z. (2015): Evaluation of physiological traits of summer maize under drought stress. - Acta Agriculturae Scandinavica, Section B - Soil \& Plant Science 66: 1-8.

[27] Zhang, W., Yu, X., Li, M., Lang, D., Zhang, X., Xie, Z. (2018): Silicon promotes growth and root yield of Glycyrrhiza uralensis under salt and drought stresses through enhancing osmotic adjustment and regulating antioxidant metabolism. - Crop Protection 107: 1-11. 